\title{
INFLUENCE OF SOCIO-PERSONAL CHARACTERISTICS ON THE ATTITUDE OF FARMERS TOWARDS INDIGENOUS WETLAND AGRICULTURAL PRACTICES
}

\author{
N. JAYAKUMAR ${ }^{1 *} \&$ M. SUNDARAMARI ${ }^{2}$ \\ ${ }^{1}$ Associate Professor (Agrl. Extension), Adhiparasakthi Agricultural College, \\ Tamil Nadu Agricultural University, Vellore, Tamil Nadu, India \\ ${ }^{2}$ Professor (Agrl. Extension), School of Agriculture \& Animal Sciences, Gandhigram Rural Institute (Deemed to be University),
} Dindigul, Tamil Nadu, India

\begin{abstract}
The study was undertaken to understand the attitude of farmers towards Indigenous Wetland Agricultural Practices. Indigenous Wetland Agricultural Practices are considered to be eco-friendly and cost effective and an antidote for reviving sustainable farming in the wetlands. They need to be sensibly promoted among the farming community. Attitude decides action and the adoption of agricultural technologies. The attitude of farmers towards IWAPs was explored by involving a sample of 209 farmers from three districts of North Eastern Agro climatic zone of Tamil Nadu. The study revealed that the mean attitudinal index was 75.70 , which indicated that majority of the farmers had a favourable attitude towards IWAPs. Majority of the respondents were above 45 years of age and engaged in agriculture with dairying. Socio personal characteristics of the farmers like Occupational status and Mass media exposure were found to have a positive and significant relationship with their attitude towards IWAPs. The study affirmed that there is a favourable shift in attitude of the farming community towards IWAPs.
\end{abstract}

KEYWORDS: Agriculture practices, Indigenous practices, Wetland practices \& Attitude

Received: Apr 02, 2020; Accepted: Apr 22, 2020; Published: May 13, 2020; Paper Id.: IJASRJUN20203

\section{INTRODUCTION}

Wetlands ecosystems cover about six per cent (6\%) of the total global land area (Turner, 1991). These wetlands are in danger of being lost due to various factors like unsustainable use, climate change and pollution, abuse of agro chemicals and rampant conversion of wetlands for commercial uses. Over millennia, the farmers in these wetlands have experimented, tested and developed an array of Indigenous Wetland Agricultural Practices (IWAPs), which are cost effective and eco-friendly. The benefits of IWAPs to multiple stakeholders' viz., nature, farmers and consumers would result in sustainable agriculture and rejuvenation of agriculture in these wetlands. Unfortunately, with modernized farming trends, indigenous practices are in the verge of extinction (Bhuyan, 2018).

There is a need to document and validate these IWAPs for present day use for ensuring sustainable development and also to preserve it for future generation to instill pride about our ancestral wisdom. Of late, many of these IWAPs have been blended with technological recommendations and promoted among the farmers.

Earlier researches have affirmed that adoption behavior of farmers is dependent upon the attitude of the farmers for a particular technology [(Nikam et al., (2014), Shitu et al., (2018), Kumar et al., (2016) and Yadav et al., (2017)]. According to Gorton, et al., (2006) policy-makers have recognized that the way in which farmers adjust to changes in agricultural policy depends partially on the latter attitudes and mind-sets. Hence, this study was taken up 
to understand the attitude of farmers towards IWAPs with the following objectives:

- To analyse the attitude of farmers towards IWAPs.

- To explore the relationship between the socio-personal characteristics of farmers and their attitude towards IWAPs.

\section{RESEARCH METHODOLOGY}

The study was conducted in the North-Eastern Agro climatic zone of Tamil Nadu with the prime objective of documenting and validating the Indigenous Wetland Agricultural Practices (IWAPs). This area was selected because it has a large acreage under agriculture with large extent under wetland farming. Out of the six districts in the zone, Kancheepuram, Thiruvallur and Thiruvannamalai were selected purposively because rice was the major crop cultivated in these three districts and with higher percentage of wetland area under rice cultivation. Block wise information on area under rice cultivation obtained from the office of the Joint Director of Agriculture of the respective districts helped in identifying ten blocks based on the total acreage under rice cultivation and area under wetland farming. From each block, two villages having the highest area under paddy cultivation were purposively selected and 209 randomly selected farmers from these villages were interviewed for the study.

Attitude was operationally defined as the degree of positive or negative effect of a farmer towards indigenous wetland practices. Attitude towards IWAPs was measured by a scale developed by Venkatesan (2012) with necessary relevant changes.

\section{FINDINGS AND DISCUSSION}

\section{Demographic Description of the Respondents}

An analysis of the socio personal characteristics of the farmers would help in understanding their behavior and reasons behind it. The study revealed that a vast majority (67.95\%) of the respondents were in the old age category. Kalimuthu (2015), Meenakshi (2015), Anyan (2018) and Suganthakumar and Philip (2018) reported similar findings. With regard to education, majority of the respondents $(61.23 \%)$ were found to have middle school to higher secondary education. Suganthakumar and Philip (2018) reported similar findings. Only 5.30 per cent of the respondents were illiterate and 15.31 per cent had collegiate education.

The study on occupational status of the respondents revealed that majority (43.54\%) did agriculture plus dairy. Kalimuthu (2015) in his study reported that a vast majority of the farmers possessed livestock and cow was the most preferred livestock among the farmers. The respondents who have agricultural income alone were accounted with 21.50 per cent. The recent trend of farmers having a dairy enterprise attached to their farm not only provides economic security to them but also serves as a source of the much needed Farm Yard Manure, which is so important to cultivation. This might be the reason why more and more farmers are going for dairying along with agriculture.

Farmers possessing 2.5 to 5 acres of land were found to be more (34.93\%) which was followed by farmers possessing 5 to 10 acres of land (26.32\%). Large percentage of the respondents $(40.67 \%)$ had high level of farming experience which was followed by 36.36 per cent with medium level of farming experience. Put together the respondents with medium to high farming experience were 77.03 per cent. The average farming experience was found to be 27 years.

Social participation refers to the degree of involvement of an individual in formal organization either as a member 
or office bearer. The study revealed that that majority of the respondents $(69.38 \%)$ were in the medium category with respect to social participation, which was followed by high category with 18.18 per cent. It was found that majority of the respondents $(38.76 \%)$ were members in at least one organization.

Extension agency contact is considered to be a deciding factor with regard to transfer of technology. It is believed that farmers who have better extension agency contact are supposed to be more exposed to the latest technologies. However, the study revealed that majority $(57.89 \%)$ of the respondents had low level of extension agency contact. Similar finding was also reported by Meenakshi (2015). This low level of extension agency contact of the respondents is a matter of concern and this situation might be due to the present scheme based approach of the Department of Agriculture wherein only the beneficiaries of the scheme are being targeted. As evident from "Table 1", only few respondents $(2.87 \%)$ had high extension agency contact. Among the extension agents, Assistant Agricultural Officers and Veterinary Doctors were the most sought after agents. This is justified as most of the respondents were engaged in agriculture plus dairy.

Mass media expedite the technology transfer process and can develop a considerable acquaintance with ultimate users very rapidly. It is quiet logical to say that message can exist in different channels, however the usage and choice of channels often is an important factor for a client. Majority $(57.42 \%)$ of the respondents were in the medium category with regard to mass media exposure. It could be concluded that a vast majority (99.53\%) were in the medium to low category with regard to mass media exposure.

Table 1: Distribution of Respondents Based on their Socio Personal Characteristics

\begin{tabular}{|c|c|c|c|c|}
\hline Sl. No. & Socio Personal Characteristics & Age Category & Frequency & Percent \\
\hline \multirow{3}{*}{1} & \multirow{3}{*}{ Age } & (Less than 35 years) & 26 & 12.44 \\
\hline & & (35 to 45 years) & 41 & 19.61 \\
\hline & & (More than 45 years) & 142 & 67.95 \\
\hline \multirow{6}{*}{2} & \multirow{6}{*}{ Educational Qualification } & Illiterate & 11 & 5.25 \\
\hline & & Functionally literate & 2 & 1.00 \\
\hline & & Primary education & 36 & 17.21 \\
\hline & & Middle school education & 71 & 33.97 \\
\hline & & Secondary school education & 57 & 27.26 \\
\hline & & Collegiate education & 32 & 15.31 \\
\hline \multirow{6}{*}{3} & \multirow{6}{*}{ Occupational status } & Agriculture + Service & 14 & 6.70 \\
\hline & & Agriculture + Business & 36 & 17.22 \\
\hline & & Agriculture + Daily wages + Dairy & 9 & 4.31 \\
\hline & & Agriculture + Dairy & 91 & 43.54 \\
\hline & & Agriculture + Daily wages & 14 & 6.70 \\
\hline & & Agriculture alone & 45 & 21.53 \\
\hline \multirow{4}{*}{4} & \multirow{4}{*}{ Farm size } & Marginal (Up to 2.5 acres) & 49 & 23.44 \\
\hline & & (2.51 to 5 acres) & 73 & 34.93 \\
\hline & & (5.01 to 10 acres) & 55 & 26.32 \\
\hline & & (Above 10 acres) & 32 & 15.31 \\
\hline \multirow{3}{*}{5} & \multirow{3}{*}{ Farming Experience } & $(<22$ years $)$ & 48 & 22.97 \\
\hline & & (22 years -41 years) & 76 & 36.36 \\
\hline & & (> 41 years $)$ & 85 & 40.67 \\
\hline \multirow{3}{*}{6} & \multirow{3}{*}{ Social participation } & $(<2$ scores $)$ & 26 & 12.44 \\
\hline & & $(2-3$ scores $)$ & 145 & 69.38 \\
\hline & & (>3 scores) & 38 & 18.18 \\
\hline
\end{tabular}




\begin{tabular}{|c|l|ll|c|c|}
\hline \multirow{3}{*}{7} & \multirow{3}{*}{ Extension agency contact } & Low & $(<6$ scores $)$ & 121 & 57.89 \\
\cline { 3 - 6 } & & Medium & $(6-12$ scores $)$ & 82 & 39.24 \\
\cline { 3 - 6 } & & High & $(>12$ scores $)$ & 6 & 2.87 \\
\hline \multirow{3}{*}{8} & \multirow{3}{*}{ Mass media exposure } & Low & $(<18.33$ scores $)$ & 88 & 42.11 \\
\cline { 3 - 7 } & & Medium & $(18.33-36.37$ scores $)$ & 120 & 57.42 \\
\cline { 3 - 7 } & & High & $(>36.37$ scores $)$ & 1 & 0.47 \\
\hline
\end{tabular}

\section{Distribution of Respondents Based on Attitude Towards IWAPs}

The attitudinal scale consisted of ten positive and ten negative statements. The respondents were asked to state their agreements with each attitudinal statement on a Likert scale. Scores of 3, 2 and 1 were assigned for the "Agree", "Undecided" and "Disagree" responses respectively for positive statements and the scores were reversed for negative statements. The attitude score of a subject was obtained by calculating the total score of the attitudinal statements agreed with. The maximum score that was possible was 60 .

"Table 2" reveals that the mean attitude score obtained was 45.42 out of 60 . It was found that the mean attitude index was found to be 75.70. Agreement with the attitudinal statements resulted in better scores and the higher mean score indicated that the respondents had favourable attitude towards IWAPs. Anyan (2018) also reported that small scale farmers had positive attitude towards indigenous knowledge. Segregation of the respondents based on cumulative frequency method revealed that majority of the respondents $(63.16 \%)$ were found to be in the medium to high category with regard to attitude towards indigenous knowledge. Similar findings were reported by Sakeerhusain (2010). Traditional practices have been practiced over decades and most of them have been assimilated into the regular farming operations. These might possibly be the reason for a relatively high favourable attitude towards indigenous wetland agricultural practices.

Table 2: Distribution of Respondents Based on Attitude towards IWAPs

\begin{tabular}{|c|c|c|c|c|c|}
\hline Sl. No. & Attitude towards IWAPs & Frequency & Per cent & Mean & SD \\
\hline 1 & (Score $1-43)$ & 77 & 36.84 & \multirow{3}{*}{45.42} & \multirow{3}{*}{6.815} \\
\hline 2 & Medium (Score $43-51)$ & 96 & 45.94 & & \\
\hline 3 & (Score $51-60)$ & 36 & 17.22 & & \\
\hline & Total & 209 & 100.00 & & \\
\hline
\end{tabular}

\section{Descriptive Analysis of the Attitudinal Statements}

In order to have a better understanding, the scale items were ranked to know which statements were more agreed upon by the farming community. The mean score obtained for each attitudinal statement was derived, ranked and presented in "Table 3".

The highest ranked statement was "Indigenous Wetland Practices are environmentally friendly". Numerous earlier studies have affirmed that indigenous practices are eco-friendly [Anaeto et. al., (2005), Sundaramari et. al., (2008), Acharya et. al., (2008) and Asiabaka, (2009)].

"IWAPs have high adaptability to the local areas" was ranked second and "IWAPs are locally available" was ranked third. Sundaramari et.al. (2008) and Karthikeyan et.al. (2006) have reported that indigenous knowledge is cost effective and readily available. 
"IWAP's are very simple and easy to understand and practice" was the fourth ranked one on the list. The reason for these scale items being ranked at the top might be because of the reason that they have dealt with solving the problems of the farmers, being economical, environmentally friendly and reduced the risk.

Table 3: Ranking the Attitudinal Statements Regarding IWAPs

\begin{tabular}{|c|c|c|}
\hline Sl. No. & Attitudinal Statements & Rank \\
\hline 1. & IWAPs are environmentally friendly & 1 \\
\hline 2. & IWAPs are efficient in solving farmers problems & 11 \\
\hline 3. & IWAPs have scientific or other rationale & 10 \\
\hline 4. & IWAPs are very simple and easy to understand and practice & 4 \\
\hline 5. & Use of IWAPs in farming reduces risks & 6 \\
\hline 6. & Availability of input will not be a problem in using IWAPs & 5 \\
\hline 7. & $\begin{array}{l}\text { IWAPs are supplementary and complementary to modern } \\
\text { technologies in agriculture }\end{array}$ & 7 \\
\hline 8. & IWAPs have high adaptability to the local areas. & 2 \\
\hline 9. & IWAPs are economical as the cost of the inputs required is very low & 8 \\
\hline 10. & IWAPs are locally available & 3 \\
\hline 11. & IWAPs does not lead to high productivity & 16 \\
\hline 12. & IWAPs are outdated & 15 \\
\hline 13. & IWAPs are baseless and short of any scientific evidence. & 13 \\
\hline 14. & $\begin{array}{l}\text { It is unwise to use IWAPs in agriculture, as it does not guarantee for } \\
\text { success }\end{array}$ & 14 \\
\hline 15. & IWAPs are superstitious & 9 \\
\hline 16. & Farmers should not use IWAPs to have better yield and profit. & 12 \\
\hline 17. & $\begin{array}{l}\text { A farmer should not adopt IWAPs when there are proven alternate } \\
\text { scientific technologies. }\end{array}$ & 18 \\
\hline 18. & IWAPs are inferior to modern technologies. & 19 \\
\hline 19. & IWAPs in agriculture are not sustainable on a long term basis. & 17 \\
\hline 20. & $\begin{array}{l}\text { It is difficult for a farmer to shift from modern ways of cultivation to } \\
\text { indigenous ways of cultivation. }\end{array}$ & 20 \\
\hline
\end{tabular}

The items with the last four ranks revealed that large number of farmers did not agree with the statement that Indigenous Wetland Practices are not sustainable on a long term basis. Most were of the view that they can adopt IWAPs even in the presence of proven modern technologies as they were not inferior to modern technologies. Most of the farmers did not agree to the statement that it was difficult to shift from modern ways to indigenous ways. This provides strength to the argument that, of late, there is a shift in attitude among the farming community towards use of Indigenous Wetland Agricultural Practices.

\section{Relationship of Socio-Personal Characteristics with Attitude towards IWAPs}

The correlation study revealed that two out of eight independent variables had a positive and significant relationship with the attitude of farmers towards IWAPs. Occupational status and Mass Media Exposure were found to have a significant relationship with the attitude towards IWAPs at $1 \%$ level of probability. The findings of correlation and regression analysis are presented in "Table 4".

Occupational status was operationalized as the regular involvement of a person in agriculture or allied activities. This plays a vital role in a person's decisions in adopting a farming practice. If farming alone is the occupation, he will have to decide very judiciously on farming practices in order to avoid risk. Indigenous practices are considered to be cost effective and eco-friendly [Anaeto et. al., (2005), Sundaramari et. al., (2008), Acharya et. al., (2008) and Asiabaka, (2009)]. So, the positive relationship of occupational status towards attitude towards IWAPs could be well justified. 
Table 4: Relationship of socio Personal Characteristics of Farmers with their Attitude towards IWAPs

\begin{tabular}{|c|c|c|c|c|c|}
\hline Sl. No. & Profile Characteristics & Correlation Coefficient & $\begin{array}{l}\text { Regression } \\
\text { co-efficient }\end{array}$ & $\begin{array}{c}\text { Standard } \\
\text { Error }\end{array}$ & $\begin{array}{l}\text { Computed } \\
\text { 't' value }\end{array}$ \\
\hline & Constant & & 32.510 & 3.187 & $10.202(* *)$ \\
\hline $\mathrm{X}_{1}$ & Age & $0.066 \mathrm{NS}$ & 0.853 & 0.748 & 0.088 \\
\hline $\mathrm{X}_{2}$ & Educational Status & $0.092 \mathrm{NS}$ & 0.791 & 0.382 & $2.073(*)$ \\
\hline $\mathrm{X}_{3}$ & Occupational Status & $0.193(* *)$ & 0.934 & 0.313 & $2.981(* *)$ \\
\hline $\mathrm{X}_{4}$ & Farm size & $0.023 \mathrm{NS}$ & 0.097 & 0.364 & 0.266 \\
\hline $\mathrm{X}_{5}$ & Farming Experience & $0.051 \mathrm{NS}$ & -0.078 & 0.045 & -1.743 \\
\hline $\mathrm{X}_{6}$ & Social Participation & $0.033 \mathrm{NS}$ & -0.124 & 0.457 & -0.271 \\
\hline $\mathrm{X}_{7}$ & Extension Agency contact & $0.077 \mathrm{NS}$ & -0.024 & 0.127 & -0.187 \\
\hline $\mathrm{X}_{8}$ & Mass Media exposure & $0.226(* *)$ & 0.428 & 0.132 & $3.252(* *)$ \\
\hline & \multicolumn{2}{|c|}{$\begin{array}{l}* \text { Correlation is significant at the } 0.05 \text { level. } \\
* * \text { Correlation is significant at the } 0.01 \text { level. } \\
\text { NS: Not significant }\end{array}$} & \multicolumn{3}{|c|}{$\begin{array}{l}\mathrm{R} \text { square value }=0.309 \\
\mathrm{~F} \text { value }=3.877(* *)\end{array}$} \\
\hline
\end{tabular}

Currently, organic farming is the trend and there is much discussion about organic agriculture in media and social forums. The exposure to such ideas through the media, sharing of knowledge and peer influence could have been the reasons for the positive attitude towards IWAPs. In earlier days, exposure to mass media, extension agency contact and innovativeness were the determinants for adopting western technologies but recent awareness about the environmental and health hazards of these westernized practices have led to a paradigm shift towards accepting time tested traditional practices.

The regression analysis revealed a $\mathrm{R}^{2}$ value of 0.309 , which shows that all the eight variables put together explained a significant variation to the tune of 30.90 per cent towards the attitude towards IWAPs. The F value was 3.877 and found to be significant at $1 \%$ probability level.

Out of the eight variables, Occupational status and Mass media exposure contributed positively and significantly at $1 \%$ probability level, while educational status contributed significantly at $5 \%$ level of probability. This revealed that a unit increase in the variables viz. 'Educational status' 'Occupational status' and 'Mass media exposure' ceteris paribus would result in an increase in a favourable attitude towards IWAPs by 2.073, 2.981 and 3.252 units respectively.

\section{CONCLUSIONS}

Indigenous Wetland Agricultural Practices (IWAPs) which are considered to be cost effective, eco-friendly and farmer friendly need to be popularized among the farming community. As cited by Anyan (2018) attitudes can be strong predictors of behaviour or the acceptance of ideas. The study revealed that the mean score was 45.42 out of 60 , which indicated a relatively high favourable attitude towards the IWAPs. Majority of the respondents were above 45 years of age and engaged in agriculture plus dairying.

The descriptive analysis of the attitudinal statements revealed that majority of the farmers agreed that IWAPs were environment friendly, adaptable to local conditions and locally available. Correlation analysis revealed that socio personal characteristics like Occupational status and Mass media exposure were found to have a positive and significant relationship with the attitude towards IWAPs. Regression analysis revealed that Educational status, Occupational status and Mass media exposure contributed significantly for a favourable attitude towards IWAPs. The analysis of the attitudinal statements confirms the belief that there is a favourable shift in attitude of the farming community towards IWAPs. 


\section{REFERENCES}

1. Acharya, C. L., Rao, A. S. and Ghosh, P. K. (2008). Managing soil health through indigenous knowledge. Indian farming, 58(2): 4-7.

2. Anaeto, C. F., Onu, D. O., MathwsNjoku, E. C. (2005). Contribution of indigenous knowledge to utilisation and conservation of biodiversity among rural household in south eastern Nigeria.

3. Anyan, F. Y. (2018). Farmers Perceptions and Attitudes towardsthe Use of Agricultural Indigenous Knowledge in Farming, Journal of Agriculture and Crops ISSN(e): 2412-6381, ISSN(p): 2413-886X Vol. 4 (6): 63-67.

4. Asiabaka, C. C. (2009). Agricultural Extension. A handbook for development Practitioners, Molsy Farm United Services, Omoku Rivers State, pp 148-152.

5. Ahmed, M. U. S. F. I. Q. U. E., R. I. F. A. T. Anwar, and M. A. Hossain. "Opportunities and limitations in practicing rainwater harvesting systems in Bangladesh." Int J Civil Eng 2.4 (2013): 67-74.

6. Bhuyan, Maneesha. (2018). Perceived Effectiveness ofIndigenous Technical Knowledge in Dairying, Journal of Extension Education, Vol. 28(3): 5703 -5708.

7. Gorton, G., Ping, H., and Lixin, H.(2006). Asset prices when agent are market-to-market, NBER working papers 12075, National Bureau of Economic Research, Inc.

8. Kalimuthu, T. (2015). A study on awareness, perception and management of the factors of climatic change on agriculture by farmers in the rice eco system, Unpub. M.Sc. (Ag) Thesis, AC \& RI, TNAU, Madurai.

9. Karthikeyan, C., Veeraragavathatham, D., Karpagam, D., and S. Ayisha Firdouse. (2006). Cow based Indigenous Technologies in Dry Farming, Indian Journal of Traditional Knowledge, Vol. 5 (1): 47-50.

10. Kumar, R., Slathia, P. S, Peshin, R., Gupta, S. K and M.S.Nain. (2016). A test to measure theknowledge of farmers about rapeseed mustard cultivation. Indian Journal of Extension Education 52(3\&4): 157-166.

11. Meenakshi, V. (2015). Documentation and validation of indigenous traditional knowledge practices in rice farming in Thanjavur district, Unpub Ph.D. Thesis, Tamil Nadu Agricultural University, Tamil Nadu.

12. Nagarajan, R., and B. A. S. A. M. M. A. Aladakatti. "Development of Low Cost Farmer Friendly Sensor for Rice Water Management." International Journal of Agricultural Science and Research 6.3 (2016).

13. Nikam V R, Singh P and Chahal V P. (2014).Attitude of farmers towards grape cultivation and export. Indian Journal of Agricultural Sciences 85(4): 592-597.

14. Rani, K., et al. "Biological Treatment Of Distillery Waste Water-An Overviewll." International Journal of General Engineering and Technology 2.4 (2013): 15-24.Rani, K., et al. "Biological Treatment Of Distillery Waste Water-An Overview ." International Journal of General Engineering and Technology 2.4 (2013): 15-24.

15. Sakeerhusain. A. (2010). Knowledge, adoption and perceived effectiveness of Indigenous Horticultural Practices in Kerala. Un pub.Ph.D. thesis, GRI (DU), Gandhigram.

16. Santheepan, S., and S. P. Ramanathan. "Investigation on AWDI method with field watertube for rice production under SRI." Internat J Agric. Sci. Res 6.3 (2016): 117-124.Santheepan, S., and S. P. Ramanathan. "Investigation on AWDI method with field watertube for rice production under SRI." Internat J Agric. Sci. Res 6.3 (2016): 117-124. 
17. Shitu, G. A, M. S.Nainand Frederick Kobba. (2018).Development of scale for assessing farmers' attitude towards precision conservation agricultural practices, Indian Journal of Agricultural Sciences 88 (3): 498-503.

18. Suganthakumar, P and H. Philip. (2018). Adaptation Strategies followed by the Rice Growers to Mitigate the Impactof Climate Change Journal of Extension Education, Vol.(1): 5996 -5999.

19. Sundaramari, M., Ganesh, S., Kannan G. S. and. Gopalsamy, K. (2008). Rationality and adoption of indigenous agricultural practices on sorghum (Sorghum bicolor) cultivation. Paper presented at the National Conference on 'Traditional Knowledge Systems, IPR and their Relevance for Sustainable Development', 24 -26 November, 2008, NISCAIR, Pusa, New Delhi.

20. Turner, K. (1991). Economics and Wetland Management. Ambio 20, 59-63.

21. Venkatesan, P. (2012). Adoption and Perceived Effectiveness of Indigenous Tribal Agricultural Practices of Kolli Hills, Tamil Nadu. Un pub. Ph.D. thesis, GRI (DU), Gandhigram.

22. Yadav, S., Godara, A. K and Nain, M. S. (2017). Attitude of farmers towards Bt cotton production technology in western Haryana. Journal of Community Mobilization and Sustainable Development 12(2): 157-62. 